UDC $613.22+316.722$

DOI: $10.21668 /$ health.risk/2020.3.10.eng

Research article

\title{
EXPOSURE ASSESSMENT AND RISK CHARACTERIZATION \\ OF N-NITROSODIMETHYLAMINE (NDMA) IN THE DIET OF CHILDREN FROM 6 TO 36 MONTHS IN HANOI, VIETNAM
}

\author{
Tran Cao Son ${ }^{1}$, Nguyen Thi Thanh Lam ${ }^{1,2}$, Vu Ngoc Tu' ${ }^{1}$, Bui Quang Dong ${ }^{1}$, \\ Le Thi Hong Hao ${ }^{1}$, Luu Quoc Toan ${ }^{2}$, N.A. Lebedeva-Neservya ${ }^{3,4}$ \\ ${ }^{1}$ National Institute for Food Control, 65 Pham Than Duat Str., Hanoi, Vietnam \\ ${ }^{2}$ Hanoi University of Public Health, 1A Duc Thang Road Str., Hanoi, Vietnam \\ ${ }^{3}$ Federal Scientific Center for Medical and Preventive Health Risk Management Technologies, 82 Monastyrskaya \\ Str., Perm, 614045, Russian Federation \\ ${ }^{4}$ Perm State University, 15 Bukireva Str., Perm, 614990, Russian Federation
}

$N$-Nitrosodimethylamine (NDMA) is a highly hepatotoxic compound and classified as group 2A according to IARC, which is probably carcinogenic to humans. The habit of consumption of grilled meat-based foods may lead to a health risk, especially in children. In this study, a food consumption survey was conducted in 4 districts (2 in urban and 2 in suburban areas) in Hanoi, Vietnam. Food samples in the diet of children from 6 to 36 months was collected and tested for NDMA by GC-MS/MS method. Total exposure dose was calculated and compared to the proposed tolerable daily intake (TDI) to characterize the risk. Among the food tested, NDMA was detected in canned puree, grilled meat and sausage. The average contents of NDMA were $1.50 \mu \mathrm{g} / \mathrm{kg}, 1.18 \mu \mathrm{g} / \mathrm{kg}$ and $0.20 \mu \mathrm{g} / \mathrm{kg}$ in grilled meat, sausage and puree, respectively. The average total daily exposure dose of NDMA was $8.23 \mathrm{ng} / \mathrm{kg}$ bw/day in all studied group, which were within the upper recommended TDI $(9.3 \mathrm{ng} / \mathrm{kg}$ bw/day). With a certain assumption, the cancer risk caused by exposure to NDMA were higher than the recommended value of WHO.

Key words: $N$-Nitrosodimethylamine, NDMA, exposure assessment, cancer risk, risk characterization, risk assessment, GC-MS/MS.

$\mathrm{N}$-Nitrosamine is a group of various condition of temperature. The major N-Nitcompounds with N-Nitroso structure, which is formed from the reaction between a nitrosating agent with a secondary amine in the rosamine compound, N-Nitrosodimethylamine (NDMA), is a highly hepatoxic compound and a potential carcinogen and has been clas-

(C) Tran Cao Son, Nguyen Thi Thanh Lam, Vu Ngoc Tu, Bui Quang Dong, Le Thi Hong Hao, Luu Quoc Toan, Lebedeva-Neservya N.A., 2020

Tran Cao Son - Head of the Laboratory for Food Toxicology and Allergens Testing (e-mail: caoson32@gmail.com; sontc@nifc.gov.vn; tel.: (+84) 904-24-81-67; ORCID: https://orcid.org/0000-0002-9779-2715).

Nguyen Thi Thanh Lam - Researcher at National Institute for Food Control (e-mail: thanhlamnguyen2308@gmail.com; tel.: (+84) 778-34-41-11; ORCID: https://orcid.org/0000-0001-9969-5591).

Vu Ngoc Tu - Researcher at the Laboratory for Food Toxicology and Allergens Testing (e-mail: vungoctu1986@gmail.com; tel.: (+84) 904-24-81-67; ORCID: https://orcid.org/0000-0003-4262-4471).

Bui Quang Dong - Researcher at the Laboratory for Food Toxicology and Allergens Testing (e-mail: quangdongbui@gmail.com; tel.: (+84) 904-24-81-67; ORCID: https://orcid.org/0000-0003-4807-727X).

Le Thi Hong Hao - PhD, Managing Director (e-mail: lethihonghao@yahoo.com; tel.: (+84) 904-24-81-67; ORCID: https:// orcid.org/0000-0003-3570-8570).

Luu Quoc Toan - Lecturer at Faculty of Environmental and Occupational Health (e-mail: lqt@huph.edu.vn; tel.: (+84) 091-22-72-95; ORCID: https://orcid.org/0000-0003-2464-5236).

Natalia A. Lebedeva-Nesevrya - Doctor of Sociological Sciences, Head of the Laboratory for Social Risks Analysis (e-mail: natnes@fcrisk.ru; tel.: +7 (342) 237-25-47; ORCID: https://orcid.org/0000-0003-3036-3542). 
sified as probably carcinogenic to human by International Agency for Research on Cancer from 1987 [1, 2]. According to U.S. Environmental Protection Agency (EPA) in a study in 1989, the lowest-observed adverse effect level (LOEAL) was established at 0.05 $\mathrm{mg} / \mathrm{kg}$ bw/day for carcinogenic effect and the no-observed adverse effect level (NOEAL) was established at $0.5 \mathrm{mg} / \mathrm{kg}$ bw/day for noncarcinogenic effect [3]. In 2007, Fitzgeral and Robinson applied mathematical models to the incidence data for hepatocellular carcinomas and hemangiosarcomas, followed by arithmetic and exponential-weight averaging of the $5 \%$ extra risk dose (mBMD 0.05) for the various models, produced an mBMD 0.05 range of $0.020-0.028 \mathrm{mg} / \mathrm{kg} \mathrm{bw} /$ day. This was then divided by a range of modifying factors to account for seriousness of the carcinogenic endpoint, adequacy of the database, and inter- and intraspecies differences, generating a TDI range of 4.0 to $9.3 \mathrm{ng} / \mathrm{kg}$ bw/day [4].

Many researches have revealed the occurrence of NDMA as well as other Nnitrosamines in foods. Food products which go through heated processing steps such as frying or grilling may pose a risk of N-nitrosamines formed by reaction between amino acids from proteins decomposition and nitrate which is preservative in food. The amount of nitrosamine formed depends on the time of preparation, temperature, and the nitrates content in the sample [5]. The content of NDMA in meat products such as grilled meat, smoked meat, canned fish ... ranges from $1-100 \mathrm{ng} / \mathrm{g}$ [6-12].

Our previous study have described a method for determination of NDMA and other N-nitrosamines using QuEChERS extraction technique combined with EI-GC-MS/MS [13]. In this study, a food consumption survey will be performed together with food collection and testing for NDMA. These data will be used for exposure assessment and risk characterization of NDMA in the diet of Vietnamese children of age from 6 to 36 months.

\section{Data and methods.}

Food consumption survey.

The survey has been carried out in medical centers, nutritional centers and private houses in 4 districts in Hanoi including Dan Phuong, Thanh Tri, Bac Tu Liem and Dong $\mathrm{Da}$, which are graphically representative for Hanoi habitants. Parents who had children of the given age $(n=480)$ were questioned in May and June of 2019. All children were divided into three age groups according to their age (group $1-6-12$ months $(29.7 \%)$; group $2-12-24$ months $(46.2 \%)$ and group 3 - 24-36 months $(24.1 \%))$. Overall distribution of children as per gender was as follows: $48.9 \%$ were girls and $51.1 \%$ were boys and this is equal to the general gender proportion for Hanoi.

\section{Food sampling.}

A total of 400 samples including rice porridge (with various kinds of meat), cereal based foods, canned purees, sausages, and processed meats were randomly collected from markets, grocery stores and supermarkets in the four studied districts. Each sample was collected at least $1 \mathrm{~kg}$, placed in air-tight sealed plastic bags, encoded and transported to National Institute of Food Control for analysis of NDMA.

\section{Analysis of NDMA.}

The method for determination of NDMA content was described previously, which contain a QuEChERS extraction step and GC-MS/MS analysis. Five grams of homogenized sample was added with internal standard (NDMA-d6) of $1 \mu \mathrm{g} / \mathrm{mL}(50 \mu \mathrm{L})$ and extracted with $10 \mathrm{~mL}$ of acetonitrile: water $(1: 1, \mathrm{v} / \mathrm{v})$ with the addition of ammonium chloride $(5.5 \mathrm{~g})$. The extract was cleaned-up with dispersive solid phase extraction containing 300 $\mathrm{mg}$ of anhydrous magnesium sulfate and 100 mg of $\mathrm{C} 18$ sorbent. $\mathrm{n}$-Hexane $(2 \mathrm{~mL})$ was used to remove the fat and then acetonitrile layer was diluted with dichloromethane (1:1) then analyzed by GC-MS/MS.

The GC-MS/MS system was a GC 7890A and a triple-quadrupole mass spectrometer 
7000B (Agilent Technologies, USA). Chromatographic separation was done on a DB 1701 column (15 m length $\cdot 0.25 \mathrm{~mm}$ i.d. $0.25 \mu \mathrm{m}$ film thickness) with a temperature ramp. The MS condition included an electron impact source and multiple reaction monitoring mode with the transitions of NDMA and the IS were $74 \rightarrow 44 ; 74 \rightarrow 42.0$ and $80 \rightarrow 50 ; 80 \rightarrow 48$, respectively.

The method was internally validated and showed good performance to be used for food analysis with the limit of detection (LOD) of $0.15 \mathrm{ng} / \mathrm{g}$.

Exposure assessment.

The exposure dose of NDMA from studied food products was calculated as follows:

$$
\begin{gathered}
(\text { Exposure dose }(\mathrm{ng} / \mathrm{kg} \mathrm{bw} / \text { day })= \\
\left.=\frac{\text { NDMA level }(\mathrm{ng} / \mathrm{g}) \cdot \text { Consumption }(\mathrm{g} / \text { day })}{\text { Body weight }(\mathrm{kg} \mathrm{bw} / \text { person })}\right) .
\end{gathered}
$$

Since the left-censored data (not detected samples) of some matrices was higher than $50 \%$, LOD was used for not detected samples. However, for the matrices that no samples were detected with NDMA, these will be withdrew from the exposure dose calculation.

\section{Risk characterization.}

The health risk of NDMA was assessed using non-carcinogen effect assessment, the exposure dose was directly compared to the TDI of 4.0 to $9.3 \mathrm{ng} / \mathrm{kg}$ bw/day which was proposed by Fitzgeral and Robinson [4].

Besides, assuming that people get exposure to the NDMA for the whole life, the cancer risk contribution of this age group due to ingestion of NDMA in food was calculated using following equation:

$$
\begin{gathered}
(\text { Cancer risk }= \\
=\frac{\text { Exposure dose }(\mathrm{ng} / \mathrm{kg} \mathrm{bw} / \text { day })}{10^{6} \cdot \text { Life time }} \times \\
\left.\times \frac{\text { Slope factor } \cdot \text { Exposure duration }}{10^{6} \cdot \text { Life time }}\right) .
\end{gathered}
$$

Since liver cancer is the major problem induced by NDMA consumption, this was chosen as the end point of health risk in this study. According to US EPA, the slope factor was estimated of 51 per $\mathrm{mg} / \mathrm{kg}$ bw/day [14], while another slope factor reported by California Office of Environmental Health Hazard Assessment was 16 per $\mathrm{mg} / \mathrm{kg}$ bw/day [15]. These was used as the upper-bound and lower-bound of cancer slope factor. The average life time of 70 years was used. In this study, the exposure duration was only 2.5 years, which will show the contribution of this period to the whole risk of cancer. However, the exposure duration of 30 years can be used assuming the exposure dose will not change over the period. The lifetime excess cancer risk level is $10^{-5}$, which based on the World Health Organization (WHO) recommendation [16].

Data analysis.

The food consumption was analyzed statistically using SPSS 16.0. The exposure dose and risk characterization were performed using Microsoft Excel.

\section{Results and discussion.}

Occurrence of NDMA.

NDMA was found in 76 out of the 80 sausages samples $(95.0 \%)$ with the concentration from 0.15 to $2.20 \mu \mathrm{g} / \mathrm{kg}$ and the average value of $1.18 \mu \mathrm{g} / \mathrm{kg} ; 79$ out of the 80 grilled or fried meat samples $(95 \%)$, with the concentration from 0.15 to $2.80 \mu \mathrm{g} / \mathrm{kg}$ and the average value of $1,50 \mu \mathrm{g} / \mathrm{kg}$. For canned puree samples, only 7 of 80 samples was detected with NDMA. Using LOD for not detected samples, the average concentration was $0.20 \mu \mathrm{g} / \mathrm{kg}$, ranged from 0.15 to $0.84 \mu \mathrm{g} / \mathrm{kg}$. NDMA was not detected in samples of rice porridge and cereal based foods.

\section{Food consumption data.}

The intake of studied foods for each age group are summarized in table 1 .

It was obvious that the main foods used for children from 6 to 36 months in Hanoi, Vietnam were from rice and other cereals. The proportion of meat-based ingredients in 
Table 1

The daily consumption of food products in Hanoi, Vietnam (mean, g/day)

\begin{tabular}{|c|c|c|c|c|c|c|}
\hline $\begin{array}{c}\text { Age groups } \\
\text { (month) }\end{array}$ & $\mathrm{N}(\%)$ & $\begin{array}{c}\text { Rice } \\
\text { porridge }\end{array}$ & $\begin{array}{c}\text { Instant } \\
\text { cereals }\end{array}$ & $\begin{array}{c}\text { Canned } \\
\text { purees }\end{array}$ & Sausages & $\begin{array}{c}\text { Process } \\
\text { meats }\end{array}$ \\
\hline 6 to 12 & $142(29.5)$ & 174.4 & 42.8 & 20.7 & 34.8 & 30.5 \\
\hline$>12$ to 24 & $223(46.5)$ & 204.1 & 69.3 & 27.4 & 36.4 & 33.7 \\
\hline$>24$ to 36 & $115(24.0)$ & 216.4 & 110.6 & 27.6 & 32.9 & 48.6 \\
\hline All: 6 to 36 & $480(100)$ & 191.8 & 66.3 & 25.2 & 35.2 & 37.6 \\
\hline
\end{tabular}

Table 2

Average exposure dose of children from 6 to 36 months

\begin{tabular}{|c|c|c|c|c|c|}
\hline \multirow{2}{*}{$\begin{array}{c}\text { Age groups } \\
\text { (month) }\end{array}$} & \multicolumn{3}{|c|}{ Exposure dose (ng/kg bw/day) } & \multirow{2}{*}{ TDI (ng/kg bw/day) } \\
\cline { 2 - 5 } & Canned purees & Sausages & Process meats & Total & \\
\hline 6 to 12 & 0.38 & 3.87 & 4.30 & 8.55 & \\
\hline$>12$ to 24 & 0.46 & 3.67 & 4.31 & 8.45 & \multirow{2}{*}{$4.0-9.3$} \\
\hline$>24$ to 36 & 0.38 & 2.72 & 5.10 & 8.20 & \\
\hline All: 6 to 36 & 0.40 & 3.32 & 4.51 & 8.23 & \\
\hline
\end{tabular}

Average exposure dose (ng/kg bw/day) by food products

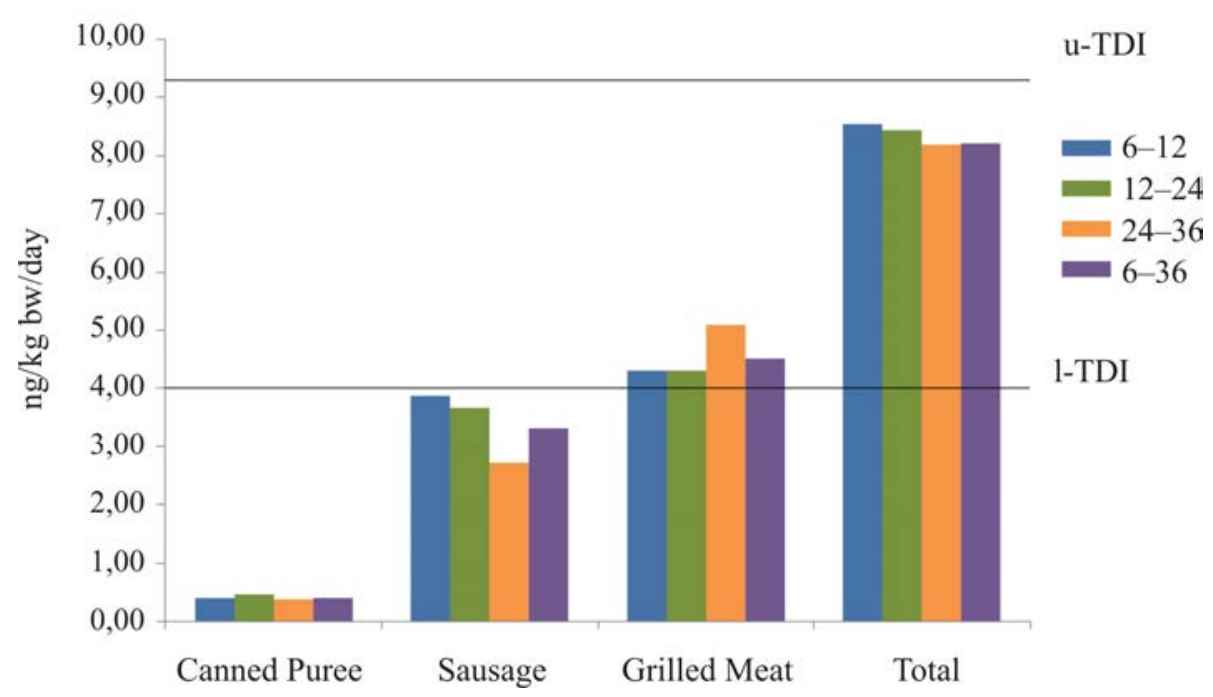

Figure. Average exposure dose by food products compared to TDI

rice porridge and instant cereals were small, which leads to a very low risk of NDMA contaminant. For this reason, these two food groups were eliminated from risk assessment. The average daily consumption of canned purees, sausages and processed meats were $25.2,35.2$ and $37.6 \mathrm{~g} /$ day, respectively. It was a surprise that children start to use sausages and grilled or fried meats from very young age (6-12 months of age).

Exposure dose and acute health risk.

The exposure doses of different age groups of children from 6 to 36 months were presented in table 2 and figure. 
Cancer risk contribution by exposure to NDMA

\begin{tabular}{|l|c|c|c|c|}
\hline \multirow{2}{*}{ Food groups } & \multicolumn{2}{|c|}{$\begin{array}{c}\text { Contribution of the studied } \\
\text { period to cancer risk }\end{array}$} & \multicolumn{2}{c|}{$\begin{array}{c}\text { Estimated cancer risk } \\
\text { with assumption }\end{array}$} \\
\cline { 2 - 5 } & Lower cancer risk & Upper cancer risk & Lower cancer risk & Upper cancer risk \\
\hline Canned purees & $0.023 \cdot 10^{-5}$ & $0.072 \cdot 10^{-5}$ & $0.273 \cdot 10^{-5}$ & $0.869 \cdot 10^{-5}$ \\
\hline Sausages & $0.190 \cdot 10^{-5}$ & $0.605 \cdot 10^{-5}$ & $2.28 \cdot 10^{-5}$ & $7.26 \cdot 10^{-5}$ \\
\hline Processed meats & $0.257 \cdot 10^{-5}$ & $0.821 \cdot 10^{-5}$ & $3.09 \cdot 10^{-5}$ & $9.85 \cdot 10^{-5}$ \\
\hline Total & $0.470 \cdot 10^{-5}$ & $1.49 \cdot 10^{-5}$ & $5.64 \cdot 10^{-5}$ & $18.0 \cdot 10^{-5}$ \\
\hline
\end{tabular}

The results of the study showed that the total exposure doses of NDMA for all food groups were in the range from 8.20 to 8.55 $\mathrm{ng} / \mathrm{kg}$ bw/day. In particular, the group of processed meats gave the highest value (4.51 ng/kg bw/day). According to the recommendations from the study of Fitzgerald and Robinson [4], the recommended TDI for NDMA ranges from 4.0 to $9.3 \mathrm{ng} / \mathrm{kg}$ bw/day. The average exposure dose of NDMA in the Vietnamese children's study showed that the values for all age groups of processed meat were greater than $4.0 \mathrm{ng} / \mathrm{kg}$ bw/day, exceeding the lower TDI (1-TDI) as recommended. The total exposure doses of NDMA were as highest as $8.55 \mathrm{ng} / \mathrm{kg}$ bw/day, which did not exceed the upper recommended TDI (u-TDI) level. This indicates that the exposure to NDMA in the products does not pose an acute health risk to children from 6 to 36 months in Hanoi, Vietnam.

\section{Cancer risk.}

The contribution to cancer risk and the estimated cancer risk with the assumption that the people will be exposure to NDMA for 30 years and the exposure dose will not change is presented in Table 3.

According to table 3, the contribution of the studied period to cancer risk were lower than the recommended value of WHO (reference value of $10^{-5}$ ) except for the total value of upper cancer risk. However, with the certain assumption, the cancer risk when consuming sausages and processed meats were higher than the reference value, which were 2.25 and 3.09 times higher, respectively (if used lower cancer slope factor) and were 7.26 and 9.85 times higher, respectively (if used upper cancer slope factor). This means that the consumption of sausages and processed meats for a long time (30 years) can be a reason for liver cancer risk.

\section{Conclusion.}

An exposure assessment and risk characterization of NDMA has been performed and show the daily intake of NDMA from foods in Vietnamese children of 6 to 36 months was within the recommended tolerable daily intake. However, the values can pose a cancer risk higher than the recommendation of WHO. These results can be used for risk communication and risk management of consuming these kinds of products in Vietnam.

Funding. The research has been done together with the joint project between the National Institute for Food Control, Vietnam and the Federal Scientific Center for Medical and Preventive Health Risk Management Technologies, Russia.

Conflict of interests. The authors declare there is no any conflict of interests. 


\section{References}

1. Lee V.M., Keefer L.K., Archer M.C. Possible mechanisms of N-nitrosodimethylamine hepatotoxicity. Nitrosamines and Related N-Nitroso Compounds, 1994, vol. 553, pp. 279-289. DOI: 10.1021/bk-1994-0553.ch022

2. IARC monographs on the evaluation of the carcinogenic risk of chemicals to humans. Vol. 17. Some N-nitroso compounds. Lyon, International Agency for Research on Cancer Publ., $1978,365 \mathrm{p}$.

3. Toxicological profile for N-nitrosodimethylamine. Atlanta, Agency for Toxic Substances and Disease Registry (ATSDR) U.S. Public Health, U.S. Environmental Protection Agency (EPA) Publ., 1989, 132 p.

4. Fitzgerald D. J., Robinson N. I. Development of a Tolerable Daily Intake for N-Nitrosodimethylamine Using a Modified Benchmark Dose Methodology. Journal of Toxicology and Environmental Health. Part A, 2007, vol. 70, no. 19, pp. 1670-1678. DOI: 10.1080/ 15287390701434844

5. Scanlan R.A. Formation and occurrence of nitrosamines in food. Cancer Research, 1983, vol. 43, no. 5, pp. 2435s-2440s.

6. Ozel M.Z., Gogus F., Yagci S., Hamilton J.F., Lewis A.C. Determination of volatile nitrosamines in various meat products using comprehensive gas chromatography-nitrogen chemiluminescence detection. Food and Chemical Toxicology, 2010, vol. 48, no. 11, pp. 3268-3273. DOI: 10.1016/j.fct.2010.08.036

7. Sannino A., Bolzoni L. GC/CI-MS/MS method for the identification and quantification of volatile N-nitrosamines in meat products. Food chemistry, 2013, vol. 141, no. 4, pp. 3925-3930. DOI: $10.1016 / \mathrm{j}$.foodchem.2013.06.070

8. Zhao Z., Xu Y., Liu X., Shi X., Lu Y. Rapid determination of 10 volatile N-nitrosamines in sour meats by modified QuEChERS and gas chromatography-triple quadrupole mass spectrometry. Chinese journal of chromatography, 2017, vol. 35, no. 10, pp. 1086-1093. DOI: 10.3724/SP.J.1123.2017.06006

9. Herrmann S.S., Duedahl-Olesen L., Granby K. Simultaneous determination of volatile and non-volatile nitrosamines in processed meat products by liquid chromatography tandem mass spectrometry using atmospheric pressure chemical ionisation and electrospray ionization. Journal of Chromatography, 2014, vol. 21, no. 133, pp. 20-29. DOI: 10.1016/j.chroma.2014.01.009

10. Y. Qiu, J.-H. Chen, W. Yu, P. Wang, M. Rong, H. Deng Contamination of Chinese salted fish with volatile N-nitrosamines as determined by QuEChERS and gas chromatographytandem mass spectrometry. Food Chemistry, 2017, vol. 1, no. 232, pp. 763-769. DOI: 10.1016/j.foodchem.2017.04.055

11. Yurchenko S., Mölder U. Volatile N-nitrosamines in various fish products. Food chemistry, 2006, vol. 96, no. 2, pp. 325-333. DOI: 10.1016/j.foodchem.2005.04.009

12. Lehotay S.J., Sapozhnikova Y., Han L., Johnston J.J. Analysis of nitrosamines in cooked bacon by QuEChERS sample preparation and gas chromatography-tandem mass spectrometry with backflushing. Journal of agricultural and food chemistry, 2015, vol. 63, no. 47, pp. 10341-10351. DOI: $10.1021 /$ acs.jafc.5b04527

13. Tran Cao Son, Bui Cao Tien, Do Thi Thu Hang, Le Thi Hong Hao Simultaneous determination of some N-nitrosamines in grilled meats by gas chromatography tandem mass spectrometry (GC-MS/MS). Journal of Analytical Science, 2018, vol. 23, no. 5, pp. 72-78.

14. Technical Fact Sheet - N-Nitroso-dimethylamine (NDMA). Washington, D.C., United States Environmental Protection Agency Publ., 2014, 7 p.

15. Technical Support Document for Cancer Potency Factors: Methodologies for derivation, listing of available values, and adjustments to allow for early life stage exposures. Sacramento, California Office of Environmental Health Hazard Assessment Publ., 2009, 89 p. 
16. N-Nitrosodimethylamine in Drinking water - Background document for development of WHO Guidelines for Drinking-water Quality. Geneva, World Health Organization Publ., $2008,37 \mathrm{p}$.

Tran Son Cao, Nguyen Thi Thanh Lam, Vu Ngoc Tu, Bui Quang Dong, Le Thi Hong Hao, Luu Quoc Toan, Lebedeva-Neservya N.A. Exposure assessment and risk characterization of n-nitrosodimethylamine (ndma) in the diet of children from 6 to 36 months in Hanoi, Vietnam. Health Risk Analysis, 2020, no. 3, pp. 86-92. DOI: 10.21668/health.risk/2020.3.10.eng

Received: 07.05.2020

Accepted: 17.08 .2020

Published: 30.09.2020 